\title{
Hybrid Algorithms for Fuzzy Reverse Supply Chain Network Design
}

\author{
Z. H. Che, ${ }^{1}$ Tzu-An Chiang, ${ }^{2}$ Y. C. Kuo, ${ }^{1}$ and Zhihua Cui ${ }^{3,4}$ \\ ${ }^{1}$ Department of Industrial Engineering and Management, National Taipei University of Technology, Taipei 10608, Taiwan \\ ${ }^{2}$ Department of Business Administration, National Taipei College of Business, Taipei 10051, Taiwan \\ ${ }^{3}$ Complex System and Computational Intelligent Laboratory, Taiyuan University of Science and Technology, Taiyuan 030024, China \\ ${ }^{4}$ State Key Laboratory for Novel Software Technology, Nanjing University, Nanjing 210023, China
}

Correspondence should be addressed to Z. H. Che; zhche@ntut.edu.tw

Received 11 October 2013; Accepted 23 December 2013; Published 24 April 2014

Academic Editors: J. Liu and K. Matsumoto

Copyright $\odot 2014$ Z. H. Che et al. This is an open access article distributed under the Creative Commons Attribution License, which permits unrestricted use, distribution, and reproduction in any medium, provided the original work is properly cited.

In consideration of capacity constraints, fuzzy defect ratio, and fuzzy transport loss ratio, this paper attempted to establish an optimized decision model for production planning and distribution of a multiphase, multiproduct reverse supply chain, which addresses defects returned to original manufacturers, and in addition, develops hybrid algorithms such as Particle Swarm Optimization-Genetic Algorithm (PSO-GA), Genetic Algorithm-Simulated Annealing (GA-SA), and Particle Swarm Optimization-Simulated Annealing (PSO-SA) for solving the optimized model. During a case study of a multi-phase, multi-product reverse supply chain network, this paper explained the suitability of the optimized decision model and the applicability of the algorithms. Finally, the hybrid algorithms showed excellent solving capability when compared with original GA and PSO methods.

\section{Introduction}

Many scholars have been devoted to the study of positive supply chains, for instance [1-5], however, the reverse supply chain has seldom been involved. Dowlatshahi [6] pointed out that reserve logistics, which is a new concept in logistics and supply chain management, offer efficient reverse logistics management that could improve the competitive power of the enterprises, especially when they face fierce competition with low-margin profits. Notwithstanding price and quality as important, influential marketing factors within a complex product path, business operations should focus on how to offer improved after-sale services to customer. Setting its target on household appliances and computers in 3C (Computers, Communications, Consumer Electronics).

Shih [7] discussed the reverse logistics system for endof-life of products, viewing reverse logistics systems as a crucial element of future business operations; more efforts should be made in reutilization, rework, and recycling at end-of-life [8]; reverse logistics is a process of recycling and refabricating materials [9]; reverse logistics is helpful to protect environments and reduce waste of resources, thus providing an opportunity for the reutilization of products. Ko and Evans [10] proposed a positive and a reverse supply chain network, based on a third party's logistics, and constructed a mixed-integer nonlinear planning model of a dynamic integrated distribution network, taking into account a two-echelon supply chain network and capacity constraints, underlining the significance of returning the defective products to the suppliers' partners. In addition, the defect ratios and transport loss ratios are fuzzy values in the real-world supply chain environments. Fuzzy defect ratios and fuzzy transport loss ratios, thus, are included in this reverse model for meeting actual conditions.

Thus, this paper focuses on the reverse supply chain and constructs an optimized decision model for the selection of supply chain partners as well as determination of production and distribution quantities. Multiechelon logistics issues could be regarded as a Knapsack of a multiple selection portfolio, and resource distribution as a NP-hard issue [11]; however, the reverse supply chain is more complex in this paper, with production defect ratios, transport loss ratios, and designated reprocessing are considered. 
GAs have been widely used in solving real-world complex optimization problems [12-16] and Min et al. [17], Sha and Che [18], Tsai [19], Ko and Evans [10], Min et al. [20], Che and Chiang [21], and Che and Chiang [22] applied GA to solve the planning issues of a supply chain network. Moreover, PSOs also have been widely employed for solving optimization problems in different fields and some heuristic algorithms with similar concept of PSO are developed [2330]. Yin and Wang [31], Yu and Fang [32], Chen et al. [33], Che and Cui [34], and Che [35] employed a PSO to optimize a resource distribution system with satisfactory results. Yet, no research efforts were made with respect to the planning of a reverse supply chain with GA and PSO. For this reason, these two heuristic algorithms were used to solve the reverse supply chain in this paper, along with other three hybrid algorithms: PSO-GA, PSO-SA, and GA-SA. The solving capability of these five algorithms was compared, and the optimum one was selected as a reference for decisionmaking.

\section{Fuzzy Theory}

Fuzzy theory, first proposed by Zaden in 1965 as an extension of a general set, is a numerical control methodology for imitating human thought and addressing the inaccuracy of all physical systems. According to Fuzzy Theory, the thought logic of human begins as fuzzy and is intended for judgment, even if conditions and data are uncertain, while modern computers feature bipolar logic, that is 0 or 1 , different from the logic of humans. However, fuzzy logic theory can represent the degree of fuzzy concepts with values between 0 and 1, namely, "membership function."

Karkowski [36] indicated that triangular is the most common membership function in solving possibilistic mathematical programming problems among the various types of membership function. Other related studies concerning the use of triangular fuzzy numbers for decision making problems are [37-40]. Hence, in this paper, the defect ratios and transport loss ratios are denoted by triangular fuzzy numbers. The triangular fuzzy numbers are not compulsory, if other types of fuzzy numbers are more applicable, they can be used.

The triangular fuzzy number can be represented as $f=\left(f_{l}, f_{m}, f_{u}\right)$, where $f_{l}, f_{m}$, and $f_{u}$ are lower bound, mode, and upper bound values, respectively. Figure 1 shows the triangular possibility distribution of fuzzy number $f$.

In addition, it is essential for practical applications that a fuzzy number should be transformed to a numerical value. The transform process is called "defuzzification." Associated ordinary number $(\mathrm{AON})$ is a simple method in defuzzification and many researches have employed it directly and effectively [41-43]. In this paper, hence, the AON is used to find the crisp value for defect and transport loss ratios. The AON method can be expressed as

$$
\operatorname{AON}(f)=\frac{f_{l}+2 f_{m}+f_{u}}{4}
$$

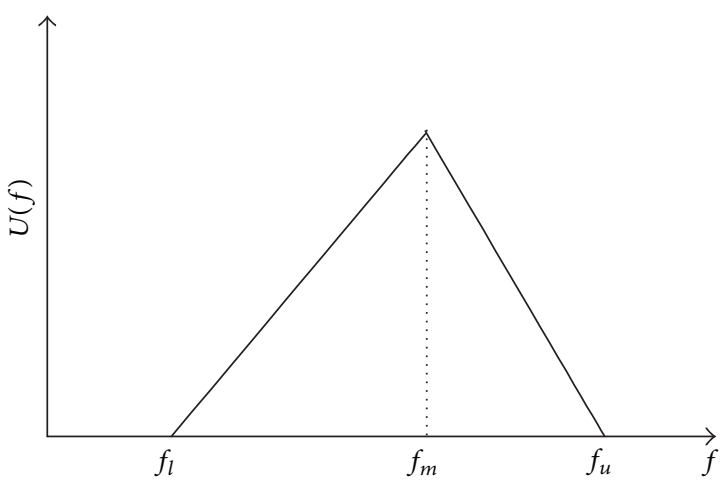

FIGURE 1: Membership functions of a triangular fuzzy number.

\section{Problem Formulation and Solving}

3.1. Description and Definition. This paper analyzed the reverse distribution activities of defective products in a complex supply chain network, and explored a method of feeding these products back to the manufacturing partners, with consideration of the capacity constraints of suppliers, and the demands of multi-phase, multi-product production and planning. Moreover, the partners shall be selected based on total objective functions (minimized production, transport, inspection, rework costs, and optimized production quality), in addition, the fuzzified production defect ratio and transport loss ratio are taken into account. Given the fact of numerous suppliers in a supply chain network, with different production characteristics and resource allocation capabilities covering their capacity and yield, it is crucial to select proper suppliers in a complex supply chain network.

Positive logistics are highlighted in a traditional supply chain, but unavoidable defects arising from production or transportation processes are overlooked. In practice, the defective products must be returned to the manufacturers. Relevant original data in this paper were subjected to $T$ treatment for data integration [44-46]. Equation (2) is a $T$-treatment formula ( $X$ : variable, $\bar{X}$ : average, SD: standard deviation).

$$
T=\frac{X-\bar{X}}{\mathrm{SD} / 10}+50
$$

3.2. Mathematical Model for Multiphase and Multiproduct Reverse Supply Chain. The mathematical symbols of a reverse supply chain one listed in the Symbols of Mathematical Model section.

The mathematical model of a multi-phase plan of a reverse supply chain is detailed as follows:

$$
\begin{aligned}
\text { Minimize } & {\left[\sum_{p=1}^{P} \sum_{i=1}^{I-1} \sum_{j=1}^{J_{i}} \sum_{k=1}^{K_{i+1}}\left(\operatorname{PrC}_{(i, j)} \times X_{((i, j),(i+1, k))}^{p}\right)\right.} \\
& +\sum_{p=1}^{P} \sum_{i=1}^{I} \sum_{j=1}^{J_{i}} \sum_{k=1}^{K_{i+1}}\left(\operatorname{TrC}_{((i, j),(i+1, k))}\right.
\end{aligned}
$$




$$
\begin{gathered}
\times\left(X_{((i, j),(i+1, k))}^{p}\right. \\
\left.\left.+R X_{((i+1, k),(i, j))}^{p}\right)\right) \\
+\sum_{p=1}^{P} \sum_{i=I}^{I} \sum_{j=1}^{J_{i}} \sum_{k=1}^{K_{i-1}}\left(\operatorname{PrC}_{(i, j)} \times X_{((i-1, k),(i, j))}^{p}\right) \\
\left.+\sum_{p=1}^{P} \sum_{i=1}^{I} \sum_{j=1}^{J_{i}} \sum_{k=1}^{K_{i+1}}\left(\operatorname{ChC}_{(i, j)} \times X_{((i, j),(i+1, k))}^{p}\right)\right] \\
\times \sum_{p=1}^{P} \sum_{i=1}^{I} \sum_{j=1}^{J_{i}} Q_{(i, j)}^{p}
\end{gathered}
$$

$$
\begin{aligned}
& \text { s.t } \sum_{k=1}^{K_{i+1}} X_{((i, j),(i+1, k))}^{p} \\
& =\mathrm{INT}\left\{\sum_{k=1}^{K_{i+1}} X_{((i, j),(i+1, k))}^{p}\right. \\
& \left.\quad \times\left(1-\mathrm{F} \mathrm{TR}_{((i, j),(i+1, k))}\right)+R X_{((i+1, k),(i, j))}^{p-1}\right\}, \\
& \quad i=1 ; \quad p=1,2,3, \ldots, P ; \quad j=1,2,3, \ldots, J
\end{aligned}
$$$$
\sum_{k=1}^{K_{i-1}} X_{((i-1, k),(i, j))}^{p}
$$$$
=\operatorname{INT}\left\{\left[\sum_{k=1}^{K_{i-1}} X_{((i-1, k),(i, j))}^{p} \times \sum_{k=1}^{K_{i+1}}\left(1-\mathrm{F} \mathrm{TR}_{((i, j),(i+1, k))}\right)\right]\right.
$$$$
\left.+\sum_{k=1}^{K_{i+1}} R X_{((i+1, k),(i, j))}^{p-1}-\sum_{k=1}^{K_{i-1}} R X_{((i, j),(i-1, k))}^{p}\right\}
$$$$
i=2, \ldots, I-1 ; \quad p=1,2,3, \ldots, P ; \quad j=1,2,3, \ldots, J,
$$$$
\sum_{k=1}^{K_{i-1}} X_{((i-1, k),(i, j))}^{p}
$$$$
=\operatorname{INT}\left\{\sum _ { k = 1 } ^ { K _ { i - 1 } } \left[X_{((i-1, k),(i, j))}^{p}\right.\right.
$$$$
\times\left(1-\mathrm{F} \mathrm{TR}_{((i, j),(i-1, k))}\right)
$$$$
\left.\left.-R X_{((i, j),(i-1, k))}^{p}\right]\right\} \text {, }
$$$$
i=I ; \quad p=1,2,3, \ldots, P ; \quad j=1,2,3, \ldots, J,
$$

$$
\begin{aligned}
& \sum_{k=1}^{K_{i-1}} R X_{((i, j),(i-1, k))}^{p} \\
& =\operatorname{INT}\left\{\left(\sum_{k=1}^{K_{i-1}} X_{((i-1, k),(i, j))}^{p}\right.\right. \\
& \left.\left.\quad+\sum_{k=1}^{K_{i+1}} R X_{((i+1, k),(i, j))}^{p-1}\right) \times{ }^{\mathrm{F}} \mathrm{DR}_{(i, j)}\right\}, \\
& i=2,3, \ldots, I ; \quad p=2,3, \ldots, P ; \quad j=1,2,3, \ldots, J,
\end{aligned}
$$

$$
\begin{aligned}
& X_{(i, j)} \\
& =\operatorname{INT}\left\{\sum_{k=1}^{K_{i+1}} X_{((i, j),(i+1, k))}^{p} \times\left(1-{ }^{\mathrm{F}} \mathrm{DR}_{(i, j)}\right)\right. \\
& \left.\times\left(1-{ }^{\mathrm{F}} \mathrm{TR}_{((i, j),(i+1, k))}\right)\right\}, \\
& i=1 ; \quad p=1,2,3, \ldots, P ; \quad j=1,2,3, \ldots, J, \\
& X_{(i, j)} \\
& =\operatorname{INT}\left\{\sum_{k=1}^{K_{i-1}} X_{((i-1, k),(i, j))}^{p} \times\left(1-{ }^{\mathrm{F}} \mathrm{DR}_{(i, j)}\right)\right. \\
& \left.\times\left(1-\mathrm{F} \mathrm{TR}_{((i, j),(i+1, k))}\right)\right\}, \\
& i=2,3, \ldots, I-1 ; \quad p=1,2,3, \ldots, P \\
& j=1,2,3, \ldots, J, \\
& \operatorname{Min}_{\mathrm{CAP}_{(i, j)}} \leq \sum_{k=1}^{K_{i+1}} X_{((i, j),(i+1, k))}^{p} \leq \operatorname{Max}_{\operatorname{CAP}}(i, j) \\
& i=1,2, \ldots, I-1 ; \quad p=1,2,3, \ldots, P ; \quad j=1,2,3, \ldots, J \\
& X_{((i, j),(i+1, k))}^{p}>0 \quad \text { and } \in \text { integer } \forall i, j, k, p \text {, } \\
& R X_{((i, j),(i-1, k))}^{p}=0 \\
& \text { for } p=0 ; i=1,2, \ldots, I \text {; } \\
& j=1,2,3, \ldots, J ; k=1,2,3, \ldots, K \text {. }
\end{aligned}
$$

Equation (3) shows objective functions involved in minimizing production costs, transport costs, rework costs, check costs, and quality (quality level 1 is defined as optimum quality, and 10 as worst quality); (4), (5), and (6) represent quantity transported from the first-hierarchy partner to the second-hierarchy partner, and finally to the partner of last hierarchy, respectively, while the fuzzy transport loss ratio and rework quantity of returned defective products are also considered; (7) represents the rework quantity of defective products to be returned to the partner of previous hierarchy; (8) and (9) indicate that limited production quantities of partners from first to last hierarchy shall meet customer demands; (10) indicates that the limited transport quantity will not be bigger than the maximum capacity, nor less than the minimum capacity of the partner; (11) indicates that the limited transport quantity must be an integer bigger than zero; and (12) indicates that no defective product is produced in the early phase of multi-product, multi-phase production planning. 
3.3. Proposed Algorithms. In this paper, GA, PSO, PSO-GA, GA-SA, and PSO-SA were applied to determine the best approximate solution, with minimum objective functions, in a reverse supply chain.

\subsubsection{GA Solving Model}

Step 1. Develop the structure of chromosome (Figure 2) and the production and transport quantities were real-coded. Eiben et al. [47] argued that real-coding could accelerate the algorithm convergence and improve consistency. In Figure 2, $P(1.1) \rightarrow P(2.1)$ represents the transport path from the first partner of the first hierarchy to the first partner of the second hierarchy, Gene value is an integral number representing the quantity of partner product transported on the distribution path.

Step 2. Generate a random initial population according to the final customer demands of the partners, restrict the population for meeting the demand constraint (4) (12), and then obtain the Fitness value by substituting the chromosome into the objective formula (3).

Step 3. Use Roulette Wheel method to select the chromosomes. Calculate selection probability of every chromosome, of which the chromosomes of better fitness function have a higher probability.

Step 4. Randomly select two chromosomes from the population for crossover, and generate random crossover points, then exchange the genes of the chromosome, as shown in Figure 3; if the crossover rate is $x_{c}$, the number of chromosomes is $y_{c}$, the crossover quantity is $x_{c} \times y_{c}=n_{c}$; a better efficiency could be achieved if crossover rate is $0.75 \sim 0.95$ [47].

Step 5. Randomly select a chromosome for mutation with its position; if the mutation rate is $x_{m}$, and the number of genes is $y_{m}$, the mutation number is $x_{m} \times y_{m}=n_{m}$, as shown in Figure 4; a higher mutation rate means a higher amplitude, a mutation rate $<0.1$ is a typical value [48].

Step 6. When the chromosomes of best offspring are superior to those of worst population, this population will be replaced as a new one.

Step 7. Repeat Steps 2 to 6 until the stop conditions are satisfied.

\subsubsection{PSO Solving Model}

Step 1. Set the particle number, iteration number, maximum speed, learning factor, and inertia weight.

Step 2. Randomly generate the initial speed and position of every particle, with the range specified in the constraint (4) (12).
Step 3. Substitute the particles of population into the objective function equation (3) to obtain the Pbest of each particle and the Gbest of the population.

Step 4. Update the speed and position of particles using Inertia Weight Method [49]; as shown in (13), when $w$ ranges between 0.9 and 1.2 , there is a higher opportunity to determine a global optimal solution [50] as follows:

$$
\begin{gathered}
v_{i}^{n}=w v_{i}^{c}+c_{1} \times \operatorname{rand}() \times\left(s_{i}^{\prime}-s_{i}^{c}\right)+c_{2} \times \operatorname{rand}() \times\left(s_{i}^{\prime \prime}-s_{i}^{c}\right), \\
s_{i}^{n}=s_{i}^{c}+v_{i}^{n},
\end{gathered}
$$

where $v_{i}^{c}$ represents the speed when the particle position is changed, $v_{i}^{n}$ is the new speed of particle $i, s_{i}^{c}$ is the current position of particle, $s_{i}^{\prime}$ is the memory value of the individual best position of particle $i, s_{i}^{\prime \prime}$ is the memory value of the global best position, $s_{i}^{n}$ is the new position of particle $i, w$ is inertia weight, $\operatorname{rand}()$ is a random variable between $(0,1)$, and $c_{1}$ and $c_{2}$ are learning factors.

Step 5. Substitute the updated particle position into the constraint (4) (12); review if the updated position meets the requirements of constraints; if any particle exceeds the range, update again until all particles meet the requirements of constraint (4) (12).

Step 6. Compare the particle's objective function value with updated particle position and its Pbest. If the objective function value is superior to the Pbest, the Pbest of this particle will be replaced by its objective function value with updated particle position.

Step 7. Compare the Pbest and Gbest. If the best value of particle is superior to Gbest, the Gbest will be replaced by the best value of the particle.

Step 8. Repeat Steps 2 to 7 until meeting the stop conditions or reaching the set iteration number.

\subsubsection{PSO-GA Solving Model}

Steps 1 3. Perform Steps 1 3 of PSO solving model.

Step 4. Perform Step 3 of GA solving model to select the particle positions of better fitness functions stored in the library. With this selection mechanism, there is a higher probability that the particle position of better fitness functions will become Gbest; another new Gbest could be obtained through recombination, and the particles could be evaluated and properly deleted, of which the worst individuals are replaced by optimum individuals, after sequencing of fitness functions. 


\begin{tabular}{|cccccccccccccccc|}
\hline \multirow{6}{*}{ Gene cell item } & $P(1.1)$ & $P(1.2)$ & $P(1.3)$ & $P(1.4)$ & $P(1.1)$ & $P(1.2)$ & $P(1.3)$ & $P(1.4)$ & & $P(3.1)$ & $P(3.2)$ & $P(3.3)$ & $P(3.1)$ & $P(3.2)$ & $P(3.3)$ \\
& $\downarrow$ & $\downarrow$ & $\downarrow$ & $\downarrow$ & $\downarrow$ & $\downarrow$ & $\downarrow$ & $\downarrow$ & $\ldots$ & $\downarrow$ & $\downarrow$ & $\downarrow$ & $\downarrow$ & $\downarrow$ & $\downarrow$ \\
& $P(2.1)$ & $P(2.1)$ & $P(2.1)$ & $P(2.1)$ & $P(2.2)$ & $P(2.2)$ & $P(2.2)$ & $P(2.2)$ & & $P(4.2)$ & $P(4.2)$ & $P(4.2)$ & $P(4.3)$ & $P(4.3)$ & $P(4.3)$ \\
\hline \multirow{3}{*}{ Gene value } & $43^{\mathrm{a}}$ & 46 & 37 & 205 & 89 & 14 & 21 & 188 & & 76 & 285 & 0 & 55 & 241 & 164 \\
& $24^{\mathrm{b}}$ & 6 & 9 & 191 & 3 & 2 & 56 & 38 & $\ldots$ & 27 & 128 & 0 & 128 & 43 & 33 \\
& $49^{\mathrm{c}}$ & 0 & 3 & 14 & 59 & 0 & 10 & 55 & & 21 & 95 & 90 & 21 & 130 & 105 \\
\hline
\end{tabular}

a: product $X \quad$ c: product $Z$

b: product $Y$

Figure 2: Structure of chromosome.

\begin{tabular}{|c|c|c|c|c|c|c|c|c|}
\hline Parent 1 & & & & & Cut po & & & \\
\hline & $P(1.1)$ & $P(1.2)$ & $P(1.3)$ & $P(1.4)$ & $P(1.1)$ & $P(1.2)$ & $P(1.3)$ & $P(1.4)$ \\
\hline Gene cell item & $P\left(\frac{1}{2} 1\right)$ & $\begin{array}{c}\downarrow \\
P(2,1)\end{array}$ & $\begin{array}{c}\downarrow \\
P(21)\end{array}$ & $\begin{array}{c}\downarrow \\
P(2) 1)\end{array}$ & $\begin{array}{c}\downarrow \\
P(2)\end{array}$ & $\begin{array}{c}\downarrow \\
P(2)\end{array}$ & $\begin{array}{c}\downarrow \\
P(2)\end{array}$ & $\begin{array}{c}\downarrow \\
P(2)\end{array}$ \\
\hline & $11^{\mathrm{a}}$ & 150 & 68 & 23 & 57 & 41 & 76 & 20 \\
\hline Gene value & $25^{\mathrm{b}}$ & 74 & 79 & 41 & 76 & 15 & 37 & 101 \\
\hline & $66^{c}$ & 81 & 14 & 39 & 22 & 52 & 90 & 38 \\
\hline Parent 2 & & & & & & & & \\
\hline & $P(1.1)$ & $P(1.2)$ & $P(1.3)$ & $P(1.4)$ & $P(1.1)$ & $P(1.2)$ & $P(1.3)$ & $P(1.4)$ \\
\hline Gene cell item & $\downarrow$ & $\downarrow$ & $\downarrow$ & $\downarrow$ & $\downarrow$ & $\downarrow$ & $\downarrow$ & $\downarrow$ \\
\hline & $P(2.1)$ & $P(2.1)$ & $P(2.1)$ & $P(2.1)$ & $P(2.2)$ & $P(2.2)$ & $P(2.2)$ & $P(2.2)$ \\
\hline & $20^{\mathrm{a}}$ & 74 & 98 & 126 & 80 & 33 & 50 & 16 \\
\hline Gene value & $44^{\mathrm{b}}$ & 56 & 86 & 93 & 21 & 88 & 13 & 29 \\
\hline & $48^{\mathrm{c}}$ & 41 & 78 & 80 & 35 & 70 & 98 & 81 \\
\hline Ofspring 1 & & & & & One pc & crossove & & \\
\hline & $P(1.1)$ & $P(1.2)$ & $P(1.3)$ & $P(1.4)$ & $P(1.1)$ & $P(1.2)$ & $P(1.3)$ & $P(1.4)$ \\
\hline Gene cell item & $\downarrow$ & $\downarrow$ & $\downarrow$ & $\downarrow$ & $\downarrow$ & $\downarrow$ & $\downarrow$ & $\downarrow$ \\
\hline & $P(2.1)$ & $P(2.1)$ & $P(2.1)$ & $P(2.2)$ & $P(2.2)$ & $P(2.2)$ & $P(2.2)$ & $P(2.2)$ \\
\hline & $11^{\mathrm{a}}$ & 15 & 68 & 23 & 80 & 33 & 50 & 16 \\
\hline Gene value & $25^{\mathrm{b}}$ & 74 & 79 & 41 & 21 & 88 & 13 & 29 \\
\hline & $66^{\mathrm{c}}$ & 81 & 14 & 39 & 35 & 70 & 98 & 81 \\
\hline Ofspring 2 & & & & & & & & \\
\hline & $P(1.1)$ & $P(1.2)$ & $P(1.3)$ & $P(1.4)$ & $P(1.1)$ & $P(1.2)$ & $P(1.3)$ & $P(1.4)$ \\
\hline item & $P\left(\frac{\downarrow}{1} 1\right)$ & $\begin{array}{c}\downarrow \\
P(2,1)\end{array}$ & $\begin{array}{c}\downarrow \\
P(21)\end{array}$ & $\begin{array}{c}\downarrow \\
P(2)\end{array}$ & $\begin{array}{c}\downarrow \\
P(2)\end{array}$ & $\begin{array}{c}\downarrow \\
P(2)\end{array}$ & $\begin{array}{c}\downarrow \\
P(2)\end{array}$ & $\begin{array}{c}\downarrow \\
P(2)\end{array}$ \\
\hline & $20^{a}$ & 74 & 98 & 126 & 57 & 41 & 76 & 20 \\
\hline Gene value & $44^{\mathrm{b}}$ & 56 & 86 & 93 & 76 & 15 & 37 & 101 \\
\hline & $48^{\mathrm{c}}$ & 41 & 78 & 80 & 22 & 52 & 90 & 38 \\
\hline
\end{tabular}

a: product $X$

c: product $Z$

b: product $Y$

FIGURE 3: Single-point crossover.

Step 5. Obtain a new group of good populations using the selection mechanism, then perform Steps 1 3 of PSO solving model and obtain the new Pbest and Gbest.

Step 6. Perform Step 5 of GA solving model to randomly select mutation particles for single-point mutation and generate a new population.

Step 7. Perform Steps 4 7 of PSO solving model to obtain the new Pbest and Gbest of the new population.

Step 8. Repeat Steps 2 to 7 until stop conditions are met.

\subsubsection{PSO-SA Solving Model}

Steps 1 6. Perform Steps 1 6 of PSO solving model.

Step 7

Substep 7.1. Set start temperature $\left(T_{\text {start }}\right)$, end temperature $\left(T_{\text {end }}\right)$, cooling rate $(\alpha)$, and length of Markov Chain $(M)$.
Substep 7.2. Disturb the updated particle under current temperature $T$, and generate a neighboring solution $k$.

Substep 7.3. Calculate the objective function, perform disturbance mechanism under current temperature to generate a neighboring solution $k$, and then substitute it into the objective function equation (5), and calculate its fitness function $f(X)$ and the difference of the fitness function $\Delta f(n)=$ $f\left(X^{\prime}\right)-f(X)$. Obtain initial solution $X$, and through iteration of random disturbances neighboring reasonable solutions, obtain a new solution $X^{\prime}$; every particle runs across the length of Markov Chain $M$ several times at start temperature $T_{\text {start }}$; a fitness is obtained every time (energy function $\Delta f(n)$ ).

Substep 7.4. Judge if this neighboring solution is accepted through probability function, using probability function (15), as shown below, and then randomly generate random number $r$ from 0 to 1 as follows:

$$
P(n)= \begin{cases}1, & \text { if } \Delta f(n) \leq 0, \\ \exp \left(\frac{-\Delta f(n)}{T}\right), & \text { if } \Delta f(n)>0,\end{cases}
$$




\begin{tabular}{|c|c|c|c|c|c|c|c|c|}
\hline Gene cell item & $\begin{array}{c}P(1.1) \\
\downarrow \\
P(2.1)\end{array}$ & $\begin{array}{c}P(1.2) \\
\downarrow \\
P(2.1)\end{array}$ & $\begin{array}{c}P(1.3) \\
\downarrow \\
P(2.1)\end{array}$ & $\begin{array}{c}P(1.4) \\
\downarrow \\
P(2.1)\end{array}$ & $\begin{array}{c}P(1.1) \\
\downarrow \\
P(2.2)\end{array}$ & $\begin{array}{c}P(1.2) \\
\downarrow \\
P(2.2)\end{array}$ & $\begin{array}{c}P(1.3) \\
\downarrow \\
P(2.2)\end{array}$ & $\begin{array}{c}P(1.4) \\
\downarrow \\
P(2.2)\end{array}$ \\
\hline Gene value & $11 / 56 / 87$ & $150 / 53 / 97$ & $17 / 68 / 76$ & $23 / 42 / 83$ & $87 / 16 / 88$ & $41 / 20 / 25$ & $46 / 91 / 75$ & $92 / 30 / 48$ \\
\hline New & L & \multicolumn{2}{|c|}{ Mutation operator } & & L & & L & \\
\hline Gene cell item & $\begin{array}{c}P(1.1) \\
\downarrow \\
P(2.1)\end{array}$ & $\begin{array}{c}P(1.2) \\
\downarrow \\
P(2.1)\end{array}$ & $\begin{array}{c}P(1.3) \\
\downarrow \\
P(2.1)\end{array}$ & $\begin{array}{c}P(1.4) \\
\downarrow \\
P(2.1)\end{array}$ & $\begin{array}{c}P(1.1) \\
\downarrow \\
P(2.2)\end{array}$ & $\begin{array}{c}P(1.2) \\
\downarrow \\
P(2.2)\end{array}$ & $\begin{array}{c}P(1.3) \\
\downarrow \\
P(2.2)\end{array}$ & $\begin{array}{c}P(1.4) \\
\downarrow \\
P(2.2)\end{array}$ \\
\hline Gene value & $20 / 79 / 64$ & $150 / 53 / 97$ & $17 / 68 / 76$ & $23 / 42 / 83$ & $57 / 37 / 75$ & $41 / 20 / 25$ & $28 / 74 / 39$ & $92 / 30 / 48$ \\
\hline
\end{tabular}

FIgURE 4: Mutation.

Substep 7.5. Compare random number $r$ with probability number $P(n)$; if $r \leq P(n)$, it will disturb the neighboring solution $k$; replace the particle and its fitness function; if $r>P(n)$, it will not replace the particle. A new disturbance solution will generate if not accepted, until the termination of set search times.

Substep 7.6. Repeat Substeps 7.2-7.5 through Markov Chain $(M)$ until $M$ times, and then perform the cooling steps, indicating that a stable state is reached under this temperature.

Substep 7.7. Implement the cooling procedure at the setcooling rate of $\alpha$ through a cooling mechanism $T=T \times \alpha$.

Substep 7.8. Judge if the cycling is finished through the set end temperature $T_{\text {end }}$, if $T \leq T_{\text {end }}$, perform the next step; if $T>$ $T_{\text {end }}$, repeat Substeps 7.2 to 7.7 until $T \leq T_{\text {end }}$.

Step 8. Repeat Steps 2 to 7 until reaching the desired iteration number.

\subsubsection{GA-SA Solving Model}

Steps 1 5. Perform Steps 1 to 5 of GA solving model.

Step 6. Perform Substeps 7.1 to 7.8 of PSO-SA solving model.

Step 7. Generate new offspring through genetic evolution; if optimum fitness function of offspring is superior to that of the population will be replaced as a new one otherwise, maintain the chromosomes of original population for next-generation evolution.

Step 8. Repeat Steps 3 to 7 until the set stop conditions are met.

\section{Illustrative Example and Results Analysis}

4.1. Case Description. In a complex supply chain network, even a leading manufacturer cannot guarantee $100 \%$ yield during the production process, or prevent any defect during the transport process. However, the defect ratio and loss ratio are not fixed; thus, fuzzy defect ratio and fuzzy transport loss ratio are applied in this paper.
Based on a supply chain network of $\{4-4-3-3\}$, this paper simulated rework activity of returned defective products through a multi-product, multi-phase production plan. Assuming that the initial inventory is zero, the defective products arising from the production process of upstream manufacturers, and from the transport process, are returned to original manufacturers for rework; the suppliers of 1st4th hierarchy have no fixed production defect ratio or transport loss ratio, meanwhile the multi-product, multiphase production is planned into three phases, with defective products only returned during the second phase. Moreover, assuming that the production defect ratio and check costs of the first-hierarchy suppliers are not considered, only the defective products from the partners of 2 nd to the 4 th are returned for rework; in addition, assume that the rework process is the same as the production process, then the rework costs and production costs are the same. According to first-phase production planning, $X$ products for final customer requirements amount to 400,350, 450, and $Y$ products amount to $250,150,200$, and $Z$ products amount to 100,200 , and 250. Figure 5 depicts the framework of a reverse supply chain and relevant parameters, including: production costs $(\mathrm{PrC})$, transport costs ( $\mathrm{TrC})$, check costs $(\mathrm{ChC})$, quality $(\mathrm{Q})$, fuzzy defect ratio ( $\left.{ }^{\mathrm{F}} \mathrm{DR}\right)$, fuzzy transport loss ratio $\left({ }^{\mathrm{F}} \mathrm{TR}\right)$, and maximum and minimum capacity (Max. CAP. and Min. CAP.). Since the production defect ratio and transport loss ratio are fuzzy sets with triangular fuzzy number, (1) is used for defuzzification. For partner $P(2.1)$, its fuzzy number of defect ratio is $(0.6 \%, 2.2 \%, 3 \%)$, then its ${ }^{\mathrm{F}} \mathrm{DR}$ is $2 \%$ according to (1). For the conciseness of this paper, the detail calculating processes of the production defect and transport loss ratios for all partners and transport paths are not presented, and their defuzzified values are shown in Figure 5.

4.2. Experimental Results and Analysis. PSO, GA, PSO-GA, GA-SA, and PSO-SA were applied for solving the distribution issues of a reverse supply chain network, the experimental design was conducted under the parameters of solving performance, of which every combination of parameters was implemented 20 times to determine an optimal combination, as listed in Table 1.

It is learnt from Table 1 that the optimal combination of PSO parameters is particle number 10 , generation number 1000 , maximum speed 1.25 , inertia weight 2.15 , and learning factor 2.05; the optimal combination of GA parameters is 
TABLE 1: Combination of experimental parameters.

\begin{tabular}{|c|c|c|c|c|c|c|c|c|c|}
\hline \multirow{8}{*}{ PSO } & Population size & 10 & 10 & 10 & 10 & 20 & 20 & 20 & 20 \\
\hline & Generations & 500 & 500 & 1000 & 1000 & 500 & 500 & 1000 & 1000 \\
\hline & Max velocity & 0.95 & 1.25 & 0.95 & 1.25 & 0.95 & 1.25 & 0.95 & 1.25 \\
\hline & Initial weight & 1.25 & 2.15 & 1.25 & 2.15 & 1.25 & 2.15 & 1.25 & 2.15 \\
\hline & $c_{1}, c_{2}$ & 2.05 & 2.05 & 2.05 & 2.05 & 2.05 & 2.05 & 2.05 & 2.05 \\
\hline & Avg. fitness & 24462289 & 24461153 & 24460103 & 24458116 & 24459087 & 24460841 & 24458923 & 24457531 \\
\hline & Avg. execution time (sec.) & 6.731 & 6.896 & 12.468 & 12.391 & 12.842 & 12.546 & 21.391 & 21.016 \\
\hline & Avg. convergence time (sec.) & 4.766 & 4.275 & 8.791 & 8.437 & 7.986 & 8.311 & 17.694 & 16.972 \\
\hline \multirow{7}{*}{ GA } & Population size & 5 & 5 & 5 & 5 & 10 & 10 & 10 & 10 \\
\hline & Generations & 500 & 500 & 1000 & 1000 & 500 & 500 & 1000 & 1000 \\
\hline & Crossover rate & 0.75 & 0.8 & 0.75 & 0.8 & 0.75 & 0.8 & 0.75 & 0.8 \\
\hline & Mutation rate & 0.08 & 0.07 & 0.08 & 0.07 & 0.08 & 0.07 & 0.08 & 0.07 \\
\hline & Avg. fitness & 24465387 & 24464085 & 24462752 & 24461924 & 24463297 & 24463159 & 244603191 & 24459450 \\
\hline & Avg. execution time (sec.) & 19.373 & 18.859 & 67.693 & 68.047 & 47.375 & 47.734 & 225.836 & 217.512 \\
\hline & Avg. convergence time (sec.) & 17.716 & 16.827 & 62.549 & 62.764 & 44.507 & 44.642 & 219.675 & 211.741 \\
\hline \multirow{9}{*}{ PSO-GA } & Population size & 10 & 10 & 10 & 10 & 20 & 20 & 20 & 20 \\
\hline & Generations & 500 & 500 & 1000 & 1000 & 500 & 500 & 1000 & 1000 \\
\hline & Max velocity & 0.95 & 1.25 & 0.95 & 1.25 & 0.95 & 1.25 & 0.95 & 1.25 \\
\hline & Initial weight & 1.25 & 2.15 & 1.25 & 2.15 & 1.25 & 2.15 & 1.25 & 2.15 \\
\hline & $c_{1}, c_{2}$ & 2.05 & 2.05 & 2.05 & 2.05 & 2.05 & 2.05 & 2.05 & 2.05 \\
\hline & Mutation rate & 0.08 & 0.07 & 0.08 & 0.07 & 0.08 & 0.07 & 0.08 & 0.07 \\
\hline & Avg. fitness & 24790482 & 24692938 & 24662117 & 24579829 & 24507556 & 24453060 & 24697893 & 24662084 \\
\hline & Avg. execution time (sec.) & 6.758 & 6.579 & 11.864 & 12.714 & 12.898 & 12.685 & 23.257 & 22.934 \\
\hline & Avg. convergence time (sec.) & 3.147 & 3.038 & 5.342 & 6.182 & 6.379 & 5.824 & 12.681 & 12.507 \\
\hline \multirow{11}{*}{ GA-SA } & Population size & 5 & 5 & 5 & 5 & 10 & 10 & 10 & 10 \\
\hline & Generations & 500 & 500 & 1000 & 1000 & 500 & 500 & 1000 & 1000 \\
\hline & Crossover rate & 0.75 & 0.8 & 0.75 & 0.8 & 0.75 & 0.8 & 0.75 & 0.8 \\
\hline & Mutation rate & 0.08 & 0.07 & 0.08 & 0.07 & 0.08 & 0.07 & 0.08 & 0.07 \\
\hline & Initial temperature & 300 & 300 & 400 & 400 & 300 & 300 & 400 & 400 \\
\hline & Markov Chain Length & 50 & 50 & 100 & 100 & 50 & 50 & 100 & 100 \\
\hline & Cooling rate & 0.9 & 0.9 & 0.99 & 0.99 & 0.9 & 0.9 & 0.99 & 0.99 \\
\hline & Final temperature & 1 & 1 & 5 & 5 & 1 & 1 & 5 & 5 \\
\hline & Avg. fitness & 24459076 & 24458365 & 24458351 & 24458067 & 24457247 & 24456391 & 24457425 & 24457544 \\
\hline & Avg. execution time (sec.) & 27.477 & 26.041 & 81.462 & 79.039 & 68.671 & 66.993 & 279.145 & 274.338 \\
\hline & Avg. convergence time (sec.) & 22.374 & 20.768 & 74.744 & 73.412 & 63.467 & 62.522 & 265.074 & 263.862 \\
\hline \multirow{12}{*}{ PSO-SA } & Population size & 10 & 10 & 10 & 10 & 20 & 20 & 20 & 20 \\
\hline & Generations & 500 & 500 & 1000 & 1000 & 500 & 500 & 1000 & 1000 \\
\hline & Max velocity & 0.95 & 1.25 & 0.95 & 1.25 & 0.95 & 1.25 & 0.95 & 1.25 \\
\hline & Initial weight & 1.25 & 2.15 & 1.25 & 2.15 & 1.25 & 2.15 & 1.25 & 2.15 \\
\hline & $c_{1}, c_{2}$ & 2.05 & 2.05 & 2.05 & 2.05 & 2.05 & 2.05 & 2.05 & 2.05 \\
\hline & Initial temperature & 300 & 300 & 400 & 400 & 300 & 300 & 400 & 400 \\
\hline & Markov Chain Length & 50 & 50 & 100 & 100 & 50 & 50 & 100 & 100 \\
\hline & Cooling rate & 0.9 & 0.9 & 0.99 & 0.99 & 0.9 & 0.9 & 0.99 & 0.99 \\
\hline & Final temperature & 1 & 1 & 5 & 5 & 1 & 1 & 5 & 5 \\
\hline & Avg. fitness & 24457588 & 24457887 & 24455842 & 24455147 & 24455895 & 24456068 & 24456457 & 24456778 \\
\hline & Avg. execution time (sec.) & 14.073 & 13.422 & 26.087 & 25.971 & 26.479 & 25.706 & 38.926 & 37.433 \\
\hline & Avg. convergence time (sec.) & 6.102 & 5.674 & 11.479 & 10.347 & 11.887 & 12.624 & 19.211 & 16.708 \\
\hline
\end{tabular}




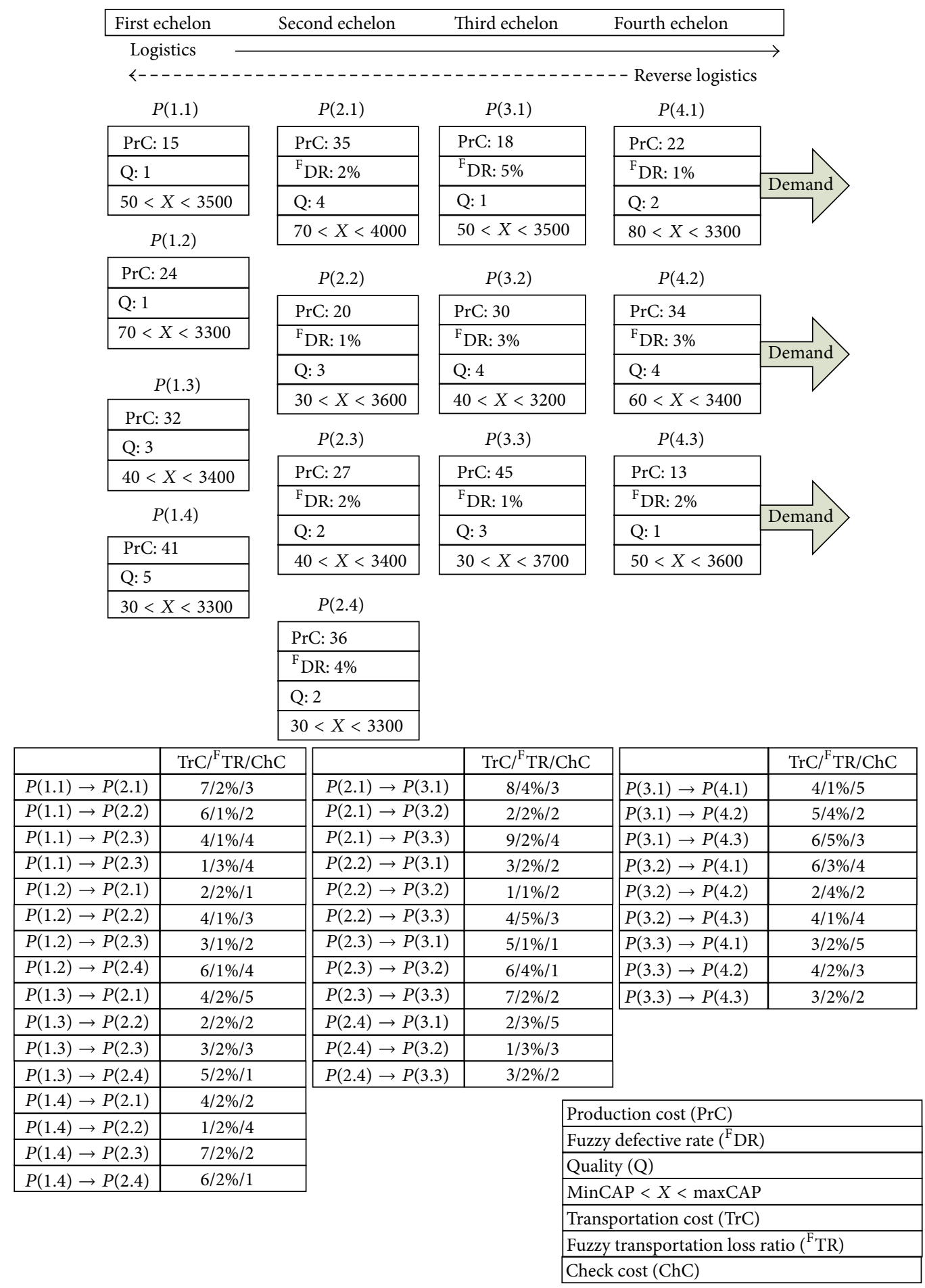

FIGURE 5: $\{4-4-3-3\}$ reverse supply chain network.

population number 10, generation number 1000, crossover rate 0.8 , and mutation rate 0.07 ; the optimal combination of PSO-GA parameters is particle number 20, generation number 500, maximum speed 1.25, inertia weight 2.15, learning factor 2.05, and mutation rate 0.07; the optimal combination of GA-SA parameters is: population number 10 , generation number 500 , crossover rate 0.8 , mutation rate 0.07 , start temperature 300, Markov Chain 50, cooling rate 0.9, and end temperature 1; the optimal combination of PSO-SA parameters is: particle number 10 , generation number 1000 , maximum speed 1.25, inertia weight 2.15, learning factor 2.05, start temperature 400, Markov Chain 100, cooling rate 0.99, end temperature 5 .

To compare the advantages and disadvantages of these algorithms, ANOVA was used to judge if convergence value, execution time, and convergence time differed considerably, 
TABLE 2: ANOVA verification of fitness values.

\begin{tabular}{|c|c|c|c|c|c|c|}
\hline \multicolumn{7}{|c|}{$\begin{aligned} \mathrm{H}_{0}:{ }^{\text {Fitness }} \mu_{\mathrm{PSO}}={ }^{\text {Fitness }} \mu_{\mathrm{GA}}={ }^{\text {Fitness }} \mu_{\mathrm{PSO}-\mathrm{GA}}={ }^{\text {Fitness }} \mu_{\mathrm{GA}-\mathrm{SA}}={ }^{\text {Fitness }} \mu_{\mathrm{PSO}-\mathrm{SA}} \\
\\
\mathrm{H}_{1}: \text { otherwise }\end{aligned}$} \\
\hline Algorithm & & & Sum & & & Variance \\
\hline PSO & & & 734139577 & 244 & & 1120394034 \\
\hline GA & & & 734406462 & 244 & & 910941494 \\
\hline PSO-GA & & & 733498321 & 244 & & 1372449396 \\
\hline GA-SA & & & 733929774 & 244 & & 752499584 \\
\hline PSO-SA & & & 733666393 & 244 & & 3467767352 \\
\hline Source & SS & Freedom & MS & $F$ & $P$ value & Critical value \\
\hline Intergroup & $1.76 E+10$ & 4 & 4389633912 & 2.87880644 & 0.02486 & 2.434065 \\
\hline Intragroup & $2.21 E+11$ & 145 & 1524810372 & & & \\
\hline Sum & $2.39 E+11$ & 149 & & & & \\
\hline
\end{tabular}

TABLE 3: ANOVA verification of execution time.

\begin{tabular}{|c|c|c|c|c|c|c|}
\hline \multicolumn{7}{|c|}{$\begin{array}{l}\text { Hypothesize } \\
={ }^{\mathrm{ET}} \mu_{\mathrm{PSO}-\mathrm{GA}}={ }^{\mathrm{ET}} \mu_{\mathrm{GA}-\mathrm{SA}}={ }^{\mathrm{ET}} \mu_{\mathrm{PSO}-\mathrm{SA}} \\
\mathrm{H}_{1} \text { : otherwise }\end{array}$} \\
\hline Algorithm & \multicolumn{2}{|r|}{ Numbers } & Sum & \multicolumn{2}{|c|}{ Average } & Variance \\
\hline PSO & \multicolumn{2}{|r|}{30} & 372.022 & \multicolumn{2}{|c|}{12.40073} & 0.076341375 \\
\hline GA & \multicolumn{2}{|r|}{30} & 6524.661 & \multicolumn{2}{|c|}{217.4887} & 0.165604217 \\
\hline PSO-GA & \multicolumn{2}{|r|}{30} & 380.424 & \multicolumn{2}{|c|}{12.6808} & 0.076438303 \\
\hline GA-SA & \multicolumn{2}{|r|}{30} & 2004.847 & \multicolumn{2}{|c|}{66.82823} & 0.187643495 \\
\hline PSO-SA & \multicolumn{2}{|r|}{30} & 775.495 & \multicolumn{2}{|c|}{25.84983} & 0.192059868 \\
\hline Source & SS & Freedom & MS & $F$ & $P$ value & Critical value \\
\hline Intergroup & 908155.7 & 4 & 227038.9 & 1626150.094 & 0.00000 & 2.434065 \\
\hline Intragroup & 20.24453 & 145 & 0.139617 & & & \\
\hline Sum & 908176 & 149 & & & & \\
\hline & & & Result: reje & & & \\
\hline
\end{tabular}

TABLE 4: ANOVA verification of convergence time.

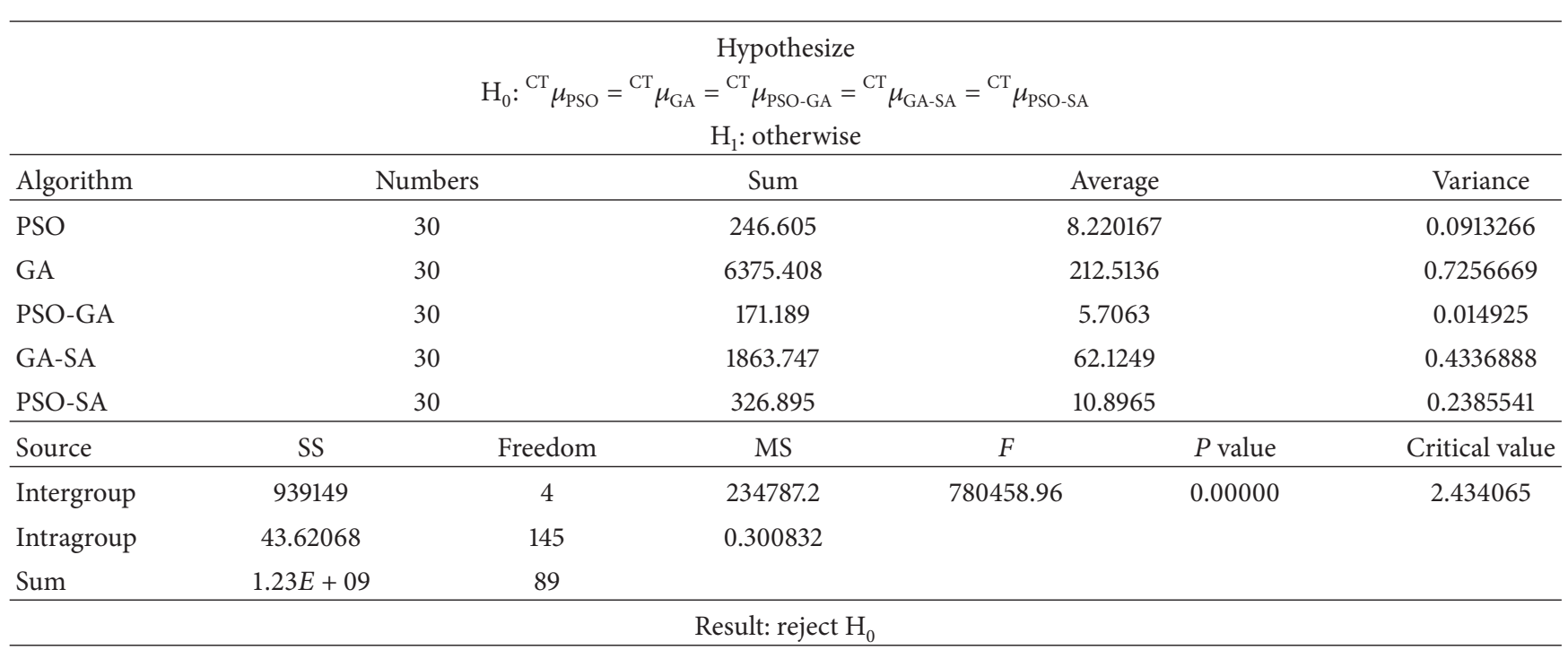


TABLE 5: Multiple comparison on fitness value.

\begin{tabular}{lccc}
\hline & ${ }^{\text {Fitness }} \mu_{\mathrm{PSO}}$ & ${ }^{\text {Fitness }} \mu_{\mathrm{GA}}$ & ${ }^{\text {Fitness }} \mu_{\mathrm{PSO}-\mathrm{GA}}$ \\
${ }^{\text {Fitness }} \mu_{\mathrm{GA}}$ & $(-,+)$ & & \\
${ }^{\text {Fitness }} \mu_{\mathrm{PSO}-\mathrm{GA}}$ & $(+,+)$ & $(+,+)$ & $\mu_{\mathrm{GA}-\mathrm{SA}}$ \\
${ }^{\text {Fitness }} \mu_{\mathrm{GA}-\mathrm{SA}}$ & $(+,+)$ & $(+,+)$ & $(-,+)$ \\
${ }_{\text {Fitness }} \mu_{\mathrm{PSO}-\mathrm{SA}}$ & $(+,+)$ & $(+,+)$ & $(-,+)$ \\
\hline
\end{tabular}

TABLE 6: Multiple comparison on execution time.

\begin{tabular}{lccc}
\hline & ${ }^{\mathrm{ET}} \mu_{\mathrm{PSO}}$ & ${ }^{\mathrm{ET}} \mu_{\mathrm{GA}}$ & ${ }^{\mathrm{ET}} \mu_{\mathrm{PSO}-\mathrm{GA}}$ \\
${ }^{\mathrm{ET}} \mu_{\mathrm{GA}}$ & $(-,-)$ & & \\
${ }^{\mathrm{ET}} \mu_{\mathrm{PSO}-\mathrm{GA}}$ & $(-,-)$ & $(+,+)$ & $(-,-)$ \\
${ }_{\mathrm{ET}} \mu_{\mathrm{GA}-\mathrm{SA}}$ & $(-,-)$ & $(+,+)$ & $(-,-)$ \\
${ }_{\mathrm{ET}} \mu_{\mathrm{PSO}-\mathrm{SA}}$ & $(-,-)$ & $(+,+)$ & $(+,+)$ \\
\hline
\end{tabular}

TABLE 7: Multiple comparison on convergence time.

\begin{tabular}{lccc}
\hline & ${ }^{\mathrm{CT}} \mu_{\mathrm{PSO}}$ & ${ }^{\mathrm{CT}} \mu_{\mathrm{GA}}$ & ${ }^{\mathrm{CT}} \mu_{\mathrm{PSO}-\mathrm{GA}}$ \\
${ }_{\mathrm{CT}} \mu_{\mathrm{GA}}$ & $(-,-)$ & & \\
${ }_{\mathrm{CT}} \mu_{\mathrm{PSO}-\mathrm{GA}}$ & $(+,+)$ & $(+,+)$ & \\
${ }_{\mathrm{CT}} \mu_{\mathrm{GA}-\mathrm{CA}}$ & $(-,-)$ & $(+,+)$ & $(-,-)$ \\
${ }^{\mathrm{CT}} \mu_{\mathrm{PSO}-\mathrm{SA}}$ & $(-,-)$ & $(+,+)$ & $(-,-)$ \\
\hline
\end{tabular}

then the algorithms were compared using Scheffe's multiple comparison method [51]; one-way ANOVA was used to check the difference of characteristics and variables [52]; Scheffe's multiple comparison method was then used to check the differences of the various groups, and whether the differences reached a significant level. Tables 2, 3, and 4 list the comparative check data of the five algorithms, which were sourced from 30 occasions of independent calculations for the optimal combination of parameters.

In Tables 2-4, the results of ANOVA verification are shown that all $\mathrm{H}_{0}$ are rejected $(P$ value $<\alpha=0.05)$. Then, the fitness value, execution time, and convergence time of the algorithms were compared using Scheffe's multiple comparison method, with Scheffe's equation as follows:

$$
\begin{aligned}
& \overline{x_{i}}-\overline{x_{j}}-\sqrt{(k-1) F_{\alpha(k-1)(n-k)}} \sqrt{\operatorname{MSE}\left(\frac{1}{n_{i}}+\frac{1}{n_{j}}\right)}, \\
& \overline{x_{i}}-\overline{x_{j}}+\sqrt{(k-1) F_{\alpha(k-1)(n-k)}} \sqrt{\operatorname{MSE}\left(\frac{1}{n_{i}}+\frac{1}{n_{j}}\right)},
\end{aligned}
$$

where $\overline{x_{i}}, \bar{x}_{j}$ are the mean values of algorithms compared, $k$ is group freedom, $F_{\alpha(k-1)(n-k)}$ is critical value, MSE is intergroup MS, $n_{i}, n_{j}$ is number of samples.

Table 5 shows ${ }^{\text {Fitness }} \mu_{\mathrm{PSO}-\mathrm{GA}}={ }^{\text {Fitness }} \mu_{\mathrm{GA}-\mathrm{SA}}=$
${ }_{\text {Fitness }}=$ GA, GA-SA, and PSO-SA are all better than PSO and GA, and there are no clear differences in the fitness values of the three algorithms. The comparative result of system execution time is shown in Table 6, and
${ }^{\mathrm{ET}} \mu_{\mathrm{PSO}}<{ }^{\mathrm{ET}} \mu_{\mathrm{PSO}-\mathrm{GA}}<{ }^{\mathrm{ET}} \mu_{\mathrm{PSO}-\mathrm{SA}}<{ }^{\mathrm{ET}} \mu_{\mathrm{GA}-\mathrm{SA}}<{ }^{\mathrm{ET}} \mu_{\mathrm{GA}}$ is the PSO is superior to other solving models. The convergence times of the algorithms are shown in Table 7, and ${ }^{\mathrm{CT}} \mu_{\mathrm{PSO}-\mathrm{GA}}<{ }^{\mathrm{CT}} \mu_{\mathrm{PSO}}<{ }^{\mathrm{CT}} \mu_{\mathrm{PSO}-\mathrm{SA}}<{ }^{\mathrm{CT}} \mu_{\mathrm{GA}-\mathrm{SA}}<{ }^{\mathrm{CT}} \mu_{\mathrm{GA}}$ PSO-GA $<$ PSO $<$ PSO-SA < GA-SA < GA; that is, PSO-GA, has faster convergence speed than PSO, PSO-SA, GA-SA, and GA. The results show that PSO-GA performs better in fitness value, execution time, and convergence time. Then, the PSO-GA is employed to make the distribution plan of three periods reverse supply chain and the results are shown in Tables 8, 9, and 10 .

\section{Conclusions}

This paper focused on analyzing the issues of returning defective products to original manufacturers in a reverse supply chain system. Fuzzy defect and fuzzy transport loss ratios were considered, and an optimized mathematical model was developed. This model combined cost and quality with T-technology and described how to plan a reverse supply chain on the precondition of meeting customer demands and realizing the capacity of partners. To solve the problems efficiently, three hybrid algorithms were applied to this reverse model, including PSO-GA, PSO-SA, and GA-SA; then, the performances of these algorithms were compared. The experimental results show that if the fitness value, execution time, and convergence time are considered, PSOGA has the minimal value, which means that PSO-GA has the qualities and capabilities for dealing with the production planning and distribution of a multi-phase, multi-product reverse supply chain. 


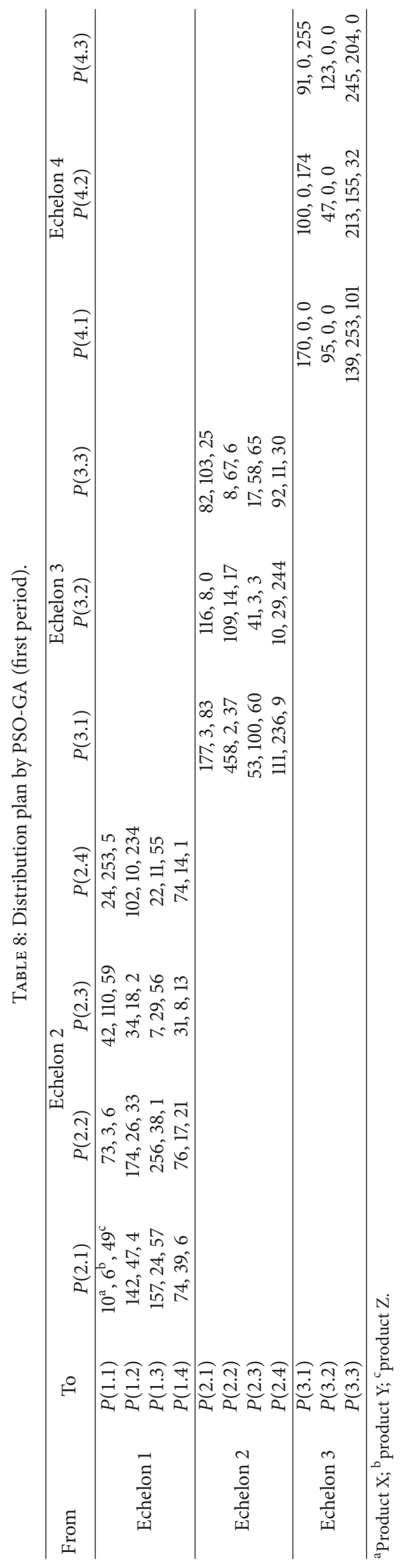




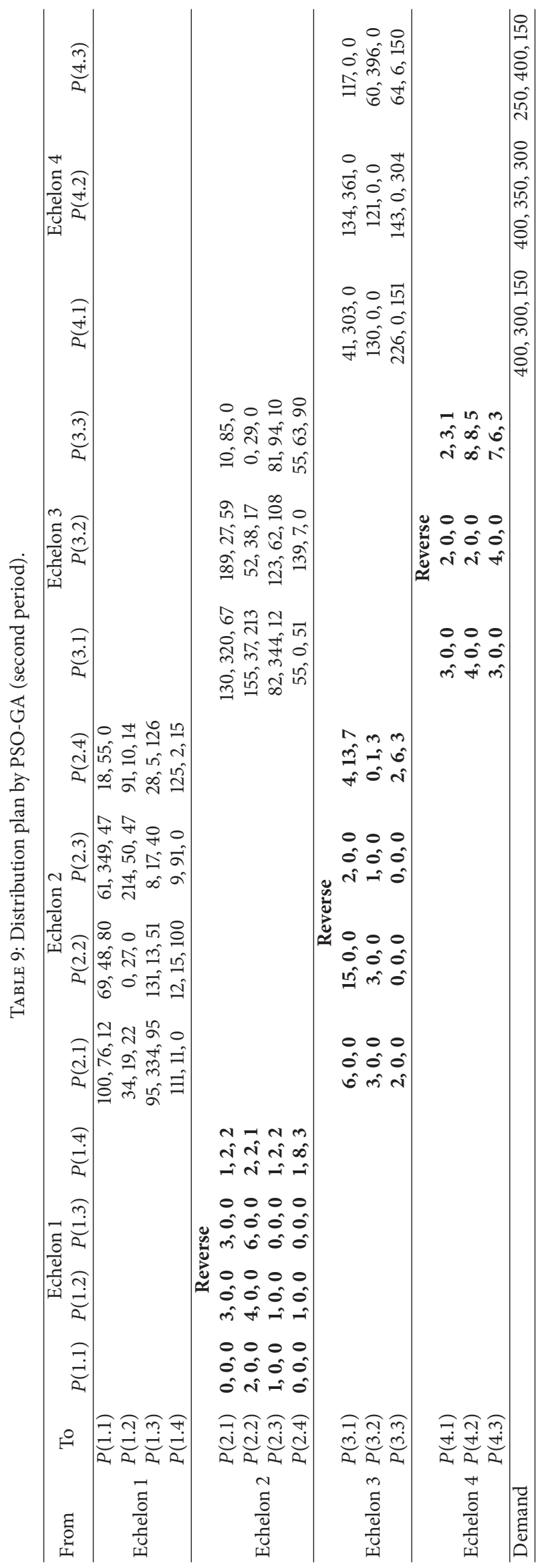




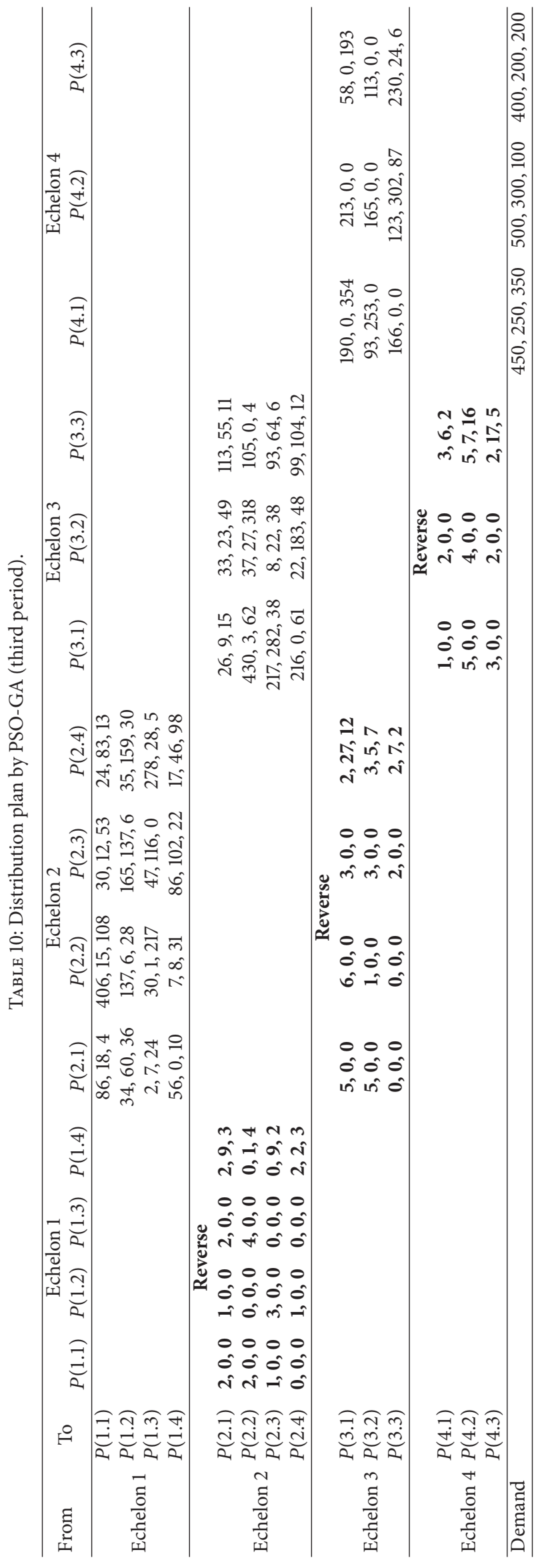




\section{Symbols of Mathematical Model}

\begin{tabular}{|c|c|}
\hline$n:$ & Number of products, $n=1,2,3, \ldots, N$ \\
\hline$N:$ & Total number \\
\hline$i$ : & Hierarchy of supply chain, $i=1,2,3, \ldots, I$ \\
\hline$I:$ & Total number of hierarchy of supply chain \\
\hline$p:$ & Production phase, $t=1,2,3, \ldots, T$ \\
\hline$P:$ & Total production phase \\
\hline$J_{i}:$ & Serial number of partner of $i$ th hierarchy \\
\hline$K_{i}:$ & $\begin{array}{l}\text { Serial number of partner of } i \text { th hierarchy } \\
\text { designated to original manufacturer }\end{array}$ \\
\hline $\mathrm{ChC}_{(i, j)}$ : & Check cost of $j$ th partner of $i$ th hierarchy \\
\hline $\operatorname{PrC}_{(i, j)}$ & $\begin{array}{l}\text { Production cost of } j \text { th partner of } i \text { th } \\
\text { hierarchy }\end{array}$ \\
\hline $\operatorname{TrC}_{((i, j),(i+1, k))}$ & $\begin{array}{l}\text { Transport cost from } j \text { th partner of } i \text { th } \\
\text { hierarchy to original (designated) partner } \\
k \text { of } i+1 \text { hierarchy }\end{array}$ \\
\hline $\mathrm{F}^{\mathrm{F}} \mathrm{TR}_{((i, j),(i+1, k))}:$ & $\begin{array}{l}\text { Fuzzy transport loss ratio from } j \text { th partner } \\
\text { of } i \text { th hierarchy to original (designated) } \\
\text { partner of } i+1 \text { hierarchy }\end{array}$ \\
\hline${ }^{\mathrm{F}} \mathrm{DR}_{(i, j)}$ : & $\begin{array}{l}\text { Fuzzy defect ratio of } j \text { th partner of } i \text { th } \\
\text { hierarchy }\end{array}$ \\
\hline$X_{(i, j)}^{p}$ : & $\begin{array}{l}\text { Production quantity of } j \text { th partner of } i \text { th } \\
\text { hierarchy at phase } p\end{array}$ \\
\hline$X_{((i, j),(i+1, k))}^{P}:$ & $\begin{array}{l}\text { Transport quantity from } j \text { th partner of } i \text { th } \\
\text { hierarchy at phase } p \text { to original } \\
\text { (designated) partner of } i+1 \text { hierarchy }\end{array}$ \\
\hline$R X_{((i+1, k)(i, j))}^{P-1}:$ & $\begin{array}{l}\text { Quantity of defective products transported } \\
\text { from } j \text { th partner of } i \text { th hierarchy at phase } \\
p-1 \text { back to original (designated) partner } \\
\text { of } i+1 \text { hierarchy }\end{array}$ \\
\hline $\operatorname{Max} \operatorname{CAP}_{(i, j)}$ : & $\begin{array}{l}\text { Maximum capacity of } j \text { th partner of } i \text { th } \\
\text { hierarchy }\end{array}$ \\
\hline $\operatorname{Min} \operatorname{CAP}_{(i, j)}$ : & $\begin{array}{l}\text { Minimum capacity of } j \text { th partner of } i \text { th } \\
\text { hierarchy }\end{array}$ \\
\hline$Q_{(i, j)}^{p}:$ & $\begin{array}{l}\text { Quality level of } j \text { th partner of } i \text { th } \\
\text { hierarchy at phase } p\end{array}$ \\
\hline $\mathrm{ChC}_{(i, j)}:$ & Check cost of $j$ th partner of $i$ th hierarchy \\
\hline $\operatorname{PrC}_{(i, j)}$ & $\begin{array}{l}\text { Production cost of } j \text { th partner of } i \text { th } \\
\text { hierarchy }\end{array}$ \\
\hline $\operatorname{Tr} \mathrm{C}_{((i, j),(i+1, k))}$ & $\begin{array}{l}\text { Transport cost from } j \text { th partner of } i \text { th } \\
\text { hierarchy to original (designated) partner } \\
k \text { of } i+1 \text { hierarchy }\end{array}$ \\
\hline $\operatorname{SD}_{(i, j)}^{Q}$ : & $\begin{array}{l}\text { Standard deviation of quality of } j \text { th } \\
\text { partner of } i \text { th hierarchy }\end{array}$ \\
\hline $\mathrm{SD}_{(i, j)}^{\mathrm{ChC}}$ : & $\begin{array}{l}\text { Standard deviation of check cost of } j \text { th } \\
\text { partner of } i \text { th hierarchy }\end{array}$ \\
\hline $\mathrm{SD}_{(i, j)}^{\mathrm{PrC}}$ & $\begin{array}{l}\text { Standard deviation of production cost of } \\
j \text { th partner of } i \text { th hierarchy }\end{array}$ \\
\hline $\mathrm{SD}_{((i, j),(i+1, k))}^{\operatorname{TrC}}$ & $\begin{array}{l}\text { Standard deviation of transport cost from } \\
j \text { th partner of } i \text { th hierarchy to original } \\
\text { (designated) partner } k \text { of } i+1 \text { hierarchy }\end{array}$ \\
\hline NT \{\} & Integer. \\
\hline
\end{tabular}

\section{Conflict of Interests}

The authors declare that there is no conflict of interests regarding the publication of this paper.

\section{Acknowledgments}

The authors would like to thank Mr. K. Hsiao for supporting writing programs and the National Science Council of Taiwan for their partial financial support (Grants nos. NSC 1022410-H-027-009 and NSC 101-2410-H-027-006). The authors would also like to acknowledge the editors and anonymous reviewers for their helpful comments and suggestions, which greatly improved the presentation of this paper.

\section{References}

[1] G. Desbarats, "The innovation supply chain," Supply Chain Management, vol. 4, no. 1, pp. 7-10, 1999.

[2] S. M. Disney, M. M. Naim, and A. Potter, "Assessing the impact of e-business on supply chain dynamics," International Journal of Production Economics, vol. 89, no. 2, pp. 109-118, 2004.

[3] T. M. Simatupang and R. Sridharan, "The collaboration index: a measure for supply chain collaboration," International Journal of Physical Distribution and Logistics Management, vol. 35, no. 1, pp. 44-62, 2005.

[4] D. Y. Sha and Z. H. Che, "Virtual integration with a multicriteria partner selection model for the multi-echelon manufacturing system," International Journal of Advanced Manufacturing Technology, vol. 25, no. 7-8, pp. 793-802, 2005.

[5] M. Tuominen and M. Anttila, "Strategising for innovation and inter-firm collaboration: capability analysis in assessing competitive superiority," International Journal of Technology Management, vol. 33, no. 2-3, pp. 214-233, 2006.

[6] S. Dowlatshahi, "Developing a theory of reverse logistics," Interfaces, vol. 30, no. 3, pp. 143-155, 2000.

[7] L.-H. Shih, "Reverse logistics system planning for recycling electrical appliances and computers in Taiwan," Resources, Conservation and Recycling, vol. 32, no. 1, pp. 55-72, 2001.

[8] A. Desai and A. Mital, "Evaluation of disassemblability to enable design for disassembly in mass production," International Journal of Industrial Ergonomics, vol. 32, no. 4, pp. 265-281, 2003.

[9] I. Dobos, "Optimal production-inventory strategies for a HMMS-type reverse logistics system," International Journal of Production Economics, vol. 81-82, pp. 351-360, 2003.

[10] H. J. Ko and G. W. Evans, "A genetic algorithm-based heuristic for the dynamic integrated forward/reverse logistics network for 3PLs," Computers and Operations Research, vol. 34, no. 2, pp. 346-366, 2007.

[11] M. Gen and R. Cheng, Genetic Algorithms and Engineering Design, John Wiley \& Sons, New York, NY, USA, 1997.

[12] B. Stojanovic, M. Milivojevic, M. Ivanovic, N. Milivojevic, and D. Divac, "Adaptive system for dam behavior modeling based on linear regression and genetic algorithms," Advances in Engineering Software, vol. 65, pp. 182-190, 2013.

[13] R. Belevičius, D. Jatulis, and D. Šešok, "Optimization of tall guyed masts using genetic algorithms," Engineering Structures, vol. 56, pp. 239-245, 2013.

[14] D. S. Hong and H. S. Cho, "A genetic-algorithm-based approach to the generation of robotic assembly sequences," Control Engineering Practice, vol. 7, no. 2, pp. 151-159, 1999.

[15] L. Özdamar, "A genetic algorithm approach to a general category project scheduling problem," IEEE Transactions on Systems, Man and Cybernetics C, vol. 29, no. 1, pp. 44-59, 1999.

[16] M. F. Sebaaly and H. Fujimoto, "Genetic planner for assembly automation," in Proceedings of the IEEE International Conference 
on Evolutionary Computation (ICEC'96), pp. 401-406, May 1996.

[17] H. Min, C. S. Ko, and H. J. Ko, “The spatial and temporal consolidation of returned products in a closed-loop supply chain network," Computers and Industrial Engineering, vol. 51, no. 2, pp. 309-320, 2006.

[18] D. Y. Sha and Z. H. Che, "Supply chain network design: partner selection and production/distribution planning using a systematic model," Journal of the Operational Research Society, vol. 57, no. 1, pp. 52-62, 2006.

[19] C.-F. Tsai, "An intelligent adaptive system for the optimal variable selections of R\&D and quality supply chains," Expert Systems with Applications, vol. 31, no. 4, pp. 808-825, 2006.

[20] H. Min, H. J. Ko, and C. S. Ko, "A genetic algorithm approach to developing the multi-echelon reverse logistics network for product returns," Omega, vol. 34, no. 1, pp. 56-69, 2006.

[21] Z. H. Che and C. J. Chiang, "A modified Pareto genetic algorithm for multi-objective build-to-order supply chain planning with product assembly," Advances in Engineering Software, vol. 41, no. 7-8, pp. 1011-1022, 2010.

[22] Z. H. Che and T. A. Chiang, "Designing a collaborative supply chain plan using the analytic hierarchy process and genetic algorithm with cycle time estimation," International Journal of Production Research, vol. 50, no. 16, pp. 4426-4443, 2012.

[23] Z. H. Che, "PSO-based back-propagation artificial neural network for product and mold cost estimation of plastic injection molding," Computers and Industrial Engineering, vol. 58, no. 4, pp. 625-637, 2010.

[24] E. García-Gonzalo and J. L. Fernández-Martínez, "A brief historical review of particle swarm optimization (PSO)," Journal of Bioinformatics and Intelligent Control, vol. 1, no. 1, pp. 3-16, 2012.

[25] L. Ali and S. L. Sabat, "Particle swarm optimization based universal solver for global optimization," Journal of Bioinformatics and Intelligent Control, vol. 1, no. 1, pp. 95-105, 2012.

[26] R. K. Sahu, S. Panda, U. K. Rout, and P. Raul, "Application of gravitational search algorithm for load frequency control of multi area power system," Journal of Bioinformatics and Intelligent Control, vol. 2, no. 3, pp. 200-210, 2013.

[27] A. S. Reddy and K. Vaisakh, "Environmental constrained economic dispatch by modified shuffled frog leaping algorithm," Journal of Bioinformatics and Intelligent Control, vol. 2, no. 3, pp. 216-222, 2013.

[28] L. P. Xie, J. C. Zeng, and R. A. Formato, "Selection strategies for gravitational constant $\mathrm{G}$ in artificial physics optimisation based on analysis of convergence properties," International Journal of Bio-Inspired Computation, vol. 4, no. 6, pp. 380-391, 2012.

[29] X. J. Cai, S. J. Fan, and Y. Tan, "Light responsive curve selection for photosynthesis operator of APOA," International Journal of Bio-Inspired Computation, vol. 4, no. 6, pp. 373-379, 2012.

[30] K. Agarwal, M. Goyal, and P. R. Srivastava, "Code coverage using intelligent water drop (IWD)," International Journal of Bio-Inspired Computation, vol. 4, no. 6, pp. 392-402, 2012.

[31] P.-Y. Yin and J.-Y. Wang, "A particle swarm optimization approach to the nonlinear resource allocation problem," Applied Mathematics and Computation, vol. 183, no. 1, pp. 232-242, 2006.

[32] J. X. Yu and X. Y. Fang, "Dynamic reactive power optimization based on particle swam optimization algorithm," East China Electric Power, vol. 34, no. 11, pp. 21-25, 2006.
[33] Y. H. Chen, W. J. Wang, and C. H. Chiu, "Particle swarm optimization algorithm and its application to power system," Henan Science, vol. 25, no. 1, pp. 29-32, 2007.

[34] Z. H. Che and Z. Cui, "Unbalanced supply chain design using the analytic network process and a hybrid heuristic-based algorithm with balance modulating mechanism," International Journal of Bio-Inspired Computation, vol. 3, no. 1, pp. 56-66, 2011.

[35] Z. H. Che, "A particle swarm optimization algorithm for solving unbalanced supply chain planning problems," Applied Soft Computing Journal, vol. 12, no. 4, pp. 1279-1287, 2012.

[36] I. Karkowski, "Architectural synthesis with possibilistic programming," in Proceedings of the 28th Annual Hawaii International Conference on System Sciences, vol. 1, pp. 14-22, 1995.

[37] R. E. Giachetti and R. E. Young, "A parametric representation of fuzzy numbers and their arithmetic operators," Fuzzy Sets and Systems, vol. 91, no. 2, pp. 185-202, 1997.

[38] J. H. Moon and C. S. Kang, "Application of fuzzy decision making method to the evaluation of spent fuel storage options," Progress in Nuclear Energy, vol. 39, no. 3-4, pp. 345-351, 2001.

[39] J. K. Cochran and H.-N. Chen, "Fuzzy multi-criteria selection of object-oriented simulation software for production system analysis," Computers and Operations Research, vol. 32, no. 1, pp. 153-168, 2005.

[40] H. K. Chiou and G. H. Tzeng, "Fuzzy hierarchical evaluation with grey relation model of green engineering for industry," International of Fuzzy System, vol. 3, pp. 466-475, 2001.

[41] Y. Tsujimura, S. Chang, and M. Gen, "Effective method for large scale project planning with multiple fuzzy activity times," in Proceedings of the 2nd IEEE International Conference on Fuzzy Systems, pp. 1009-1015, April 1993.

[42] J. G. Greenhut, G. Norman, and C. Temponi, "Toward a fuzzy theory of oligopolistic competition," in Proceedings of the 3rd International Symposium on Uncertainty Modeling and Analysis and Annual Conference of the North American Fuzzy Information Processing Society (ISUMA-NAFIPS'95), pp. 286291, September 1995.

[43] S. Petrovic and C. Fayad, "A fuzzy shifting bottleneck hybridised with genetic algorithm for real-world job shop scheduling," in Proceedings of the Mini-EURO Conference, Managing Uncertainty in Decision Support Models, C. H. Antunes and L. C. Dias, Eds., pp. 1-6, Coimbra, Portugal, 2004.

[44] G. C. Huang and P. k. Wu, "The Development of a standardized mathematics. Achievement test for seventh graders and its related study: analyzed with IRT,' Journal of Educational Research and Development, vol. 2, pp. 109-142, 2006.

[45] H. S. Wang and Z. H. Che, "An integrated model for supplier selection decisions in configuration changes," Expert Systems with Applications, vol. 32, no. 4, pp. 1132-1140, 2007.

[46] M. Y. Liou and C. M. Lu, "Application of the transtheoretical model to smoking behavior among freshmen," Journal of Health Education, vol. 24, pp. 47-70, 2005.

[47] Á. E. Eiben, R. Hinterding, and Z. Michalewicz, "Parameter control in evolutionary algorithms," IEEE Transactions on Evolutionary Computation, vol. 3, no. 2, pp. 124-141, 1999.

[48] W. D. Kelton, R. P. Sadowski, and D. A. Sadowski, Simulation with ARENA, McGraw-Hill, New York, NY, USA, 1998.

[49] Y. Shi and R. C. Eberhart, "Comparison between genetic algorithms and particle swarm optimization," in Proceedings of the 7th International Conference on Evolutionary Programming VII, vol. 1447, pp. 611-616, 1998. 
[50] Y. Shi and R. Eberhart, "Modified particle swarm optimizer," in Proceedings of the 1998 IEEE International Conference on Evolutionary Computation (ICEC'98), pp. 69-73, May 1998.

[51] H. Schee, "A method for judging all contrasts in the analysis of variance," Biometrica, vol. 40, no. 1-2, pp. 87-104, 1953.

[52] C. C. Shen and C. Y. Hsieh, "A study on the relationship among attraction, tourist satisfaction and loyalty of religious tourism a case of Fo Guang Shan in Kaohsiung," Tourism Management Research, vol. 3, no. 1, pp. 79-95, 2003. 

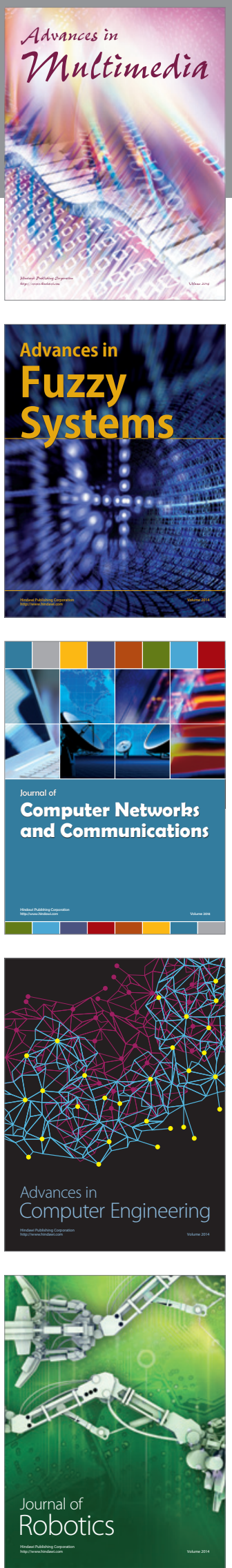

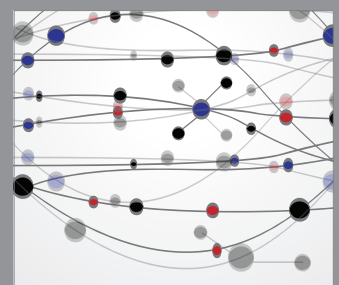

The Scientific World Journal
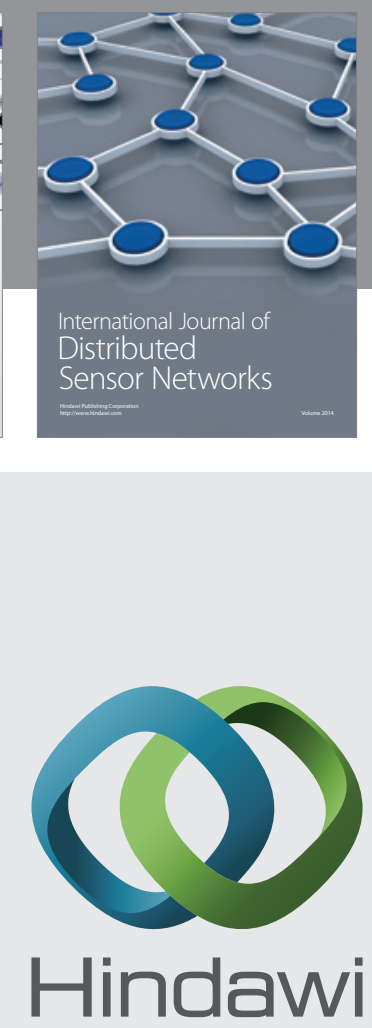

Submit your manuscripts at

http://www.hindawi.com
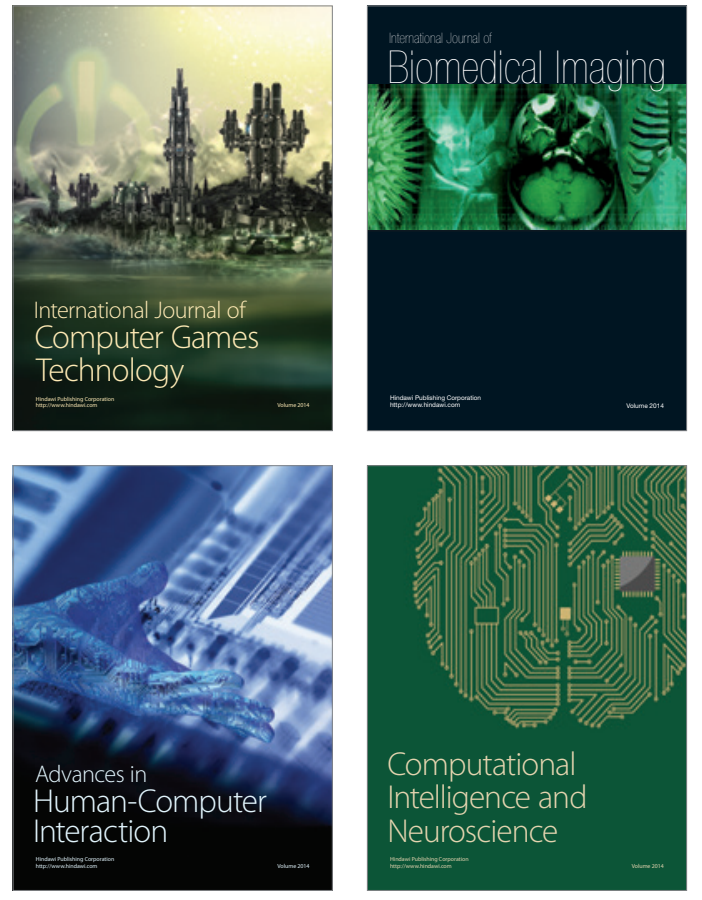
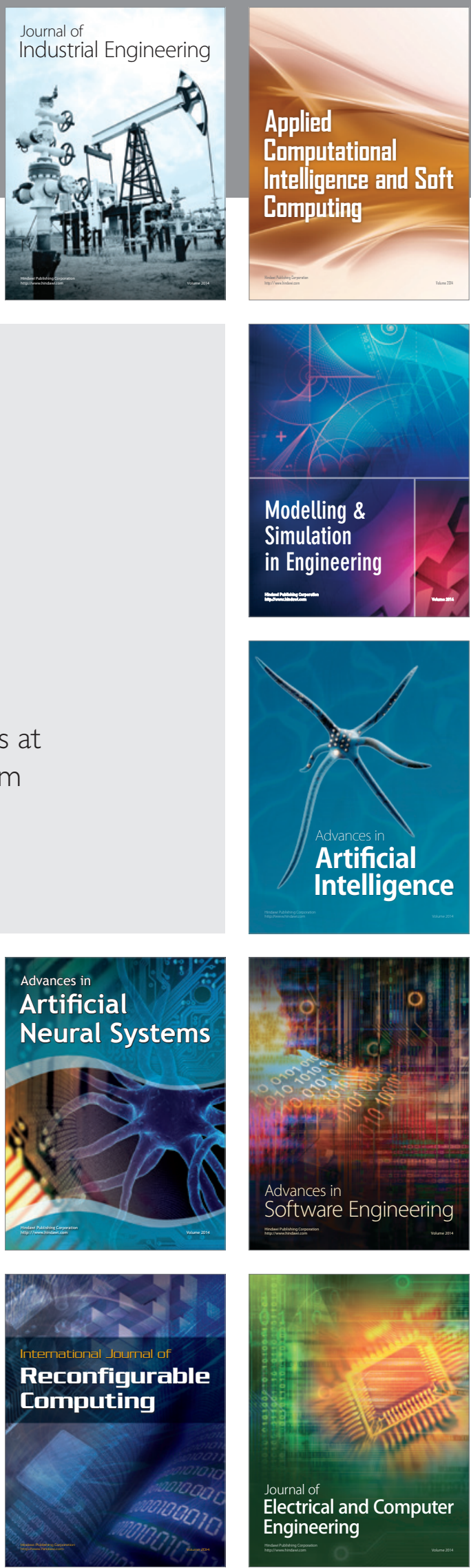